\title{
Patients presenting with Addison's disease need not be pigmented
}

\author{
ANTHONY H. BARNETT \\ M.D., M.R.C.P.
}

\author{
ERIC A. ESPINER \\ M.D., F.R.A.C.P.
}

\author{
RICHARD A. DONALD \\ PhD., F.R.A.C.P.
}

\begin{abstract}
Department of Endocrinology, Princess Margaret Hospital, Christchurch, New Zealand
\end{abstract}
\begin{abstract}
Summary
Three consecutive cases of Addison's disease without increased pigmentation are described. We suggest that the absence of this important physical sign contributed to serious delays in diagnosis and markedly increased morbidity. We emphasize that, despite the usual textbook description, excess pigmentation is not necessarily a feature of Addison's disease.
\end{abstract}

\section{Introduction}

Addison's disease is a life-threatening, treatable disorder relying heavily on a high index of clinical suspicion for diagnosis. Addison originally described the common features as: 'anaemia, general languor and debility, remarkable feebleness of the heart's action, irritability of the stomach, and a peculiar change of colour in the skin' (Addison, 1855). The most striking physical finding in the patient with Addison's disease is the increased pigmentation of the skin and mucous membranes which is said to occur in $92 \%$ of patients (Nerup, 1974). We report three consecutive cases presenting with Addison's disease, none of whom showed increased pigmentation. The absence of this important physical sign we believe contributed to serious delays in diagnosis.

\section{Case reports}

Case 1

A 59-year-old woman fractured her sternum in a car crash. On investigation mild hyponatraemia was noted, but not followed up. After discharge she was unwell with nausea, vomiting and weakness. On readmission, the endocrine team obtained an 8-year history of loss of energy and a one-year history of

Requests for reprints to: Professor E. A. Espiner. postural dizziness, intermittent nausea and vomiting, poor memory and concentration. She had been arrested some months before for shoplifting, but the charges had been dismissed on the grounds of diminished responsibility-a psychiatrist and a neurologist had both considered the patient had early dementia. There was no history of tuberculosis and no family history of auto-immune disease.

On examination she was drowsy, mildly dehydrated, blood pressure $80 / 60 \mathrm{mmHg}$ lying, with no excess pigmentation of the body or buccal mucosa. Investigations demonstrated a normochromic anaemia (haemoglobin $11 \mathrm{~g} / \mathrm{dl}$ ) with a $12 \%$ eosinophilia, plasma sodium $125 \mathrm{mmol} / \mathrm{l}$, potassium 5.0 mmol/l, creatinine $186 \mu \mathrm{mol} / 1$, urea $12.0 \mathrm{mmol} / \mathrm{l}$. She had been given $0.2 \mathrm{~N}$ saline in dextrose by the admitting team which had caused a further fall in plasma sodium to $115 \mathrm{mmol} / 1$ and a convulsion. With rehydration and steroids, renal function improved and the electrolytes returned to normal. A tetracosactrin (Synacthen) test just before steroid administration produced a poor response in plasma cortisol (cortisol increment $108 \mathrm{nmol} / \mathrm{l}$, nor$\mathrm{mal}>300$ ) and a prolonged ACTH stimulation employing zinc Synacthen for 3 days also failed to stimulate plasma cortisol (highest cortisol 186 nmol/1). Plasma renin activity (PRA) was markedly elevated (29-45 $\mathrm{nmol} / \mathrm{l}$ per hr, normal 0.4-2.4) with simultaneous low plasma aldosterone $(83 \mathrm{pmol} / \mathrm{l}$, normal range $140-550 \mathrm{pmol} / 1)$ proving mineralocorticoid deficiency. Likewise, plasma ACTH was elevated at $>400 \mathrm{ng} / 1$ (normal 0-85 ng/l) when plasma cortisol was $167 \mathrm{nmol} /$ litre. A further ACTH was 816 ng/litre. Repeat PRA and ACTH after treatment were $0.18 \mathrm{nmol} / 1 \mathrm{per} \mathrm{hr}$ and $40 \mathrm{ng} / \mathrm{l}$ respectively. She was discharged on maintenance therapy and subsequent psychological testing demonstrated normal function in short and long-term memory and verbal and spatial intellectual function. 


\section{Case 2}

A 63-year-old man was admitted acutely with a 6week history of malaise and 24-hr history of pleuritic chest pain, weakness and drowsiness. There was a past history of tuberculosis of the spine when aged 20 years, and of a 'collapse' when age 40 years, at which time he was told his adrenal glands were calcified. No follow-up was undertaken, but he had suffered from recurrent faintness, sweating and exertional weakness, relieved by food. He specifically denied change in skin colour.

On examination he was shocked with blood pressure $60 / 0 \mathrm{~mm} \mathrm{Hg}$. There was no suggestion of increased pigmentation except possibly around the genitalia. The pinnae of the ears were heavily calcified. The electrocardiogram was normal and chest X-ray showed old apical scaring and abdominal film adrenal calcification. The admitting team made a diagnosis of cardiogenic shock secondary to myocardial infarction and suspected adrenal insufficiency. He was treated with dobutamine infusion and large doses of i.v. hydrocortisone and improved after $48 \mathrm{hr}$. When seen by the endocrine team one week later, his hydrocortisone treatment was changed to dexamethasone $2 \mathrm{mg}$ daily and tests of adrenal function undertaken. Prolonged ACTH stimulation over 4 days showed no increase in plasma cortisol (maximum value $180 \mathrm{nmol} / \mathrm{l}$ ). PRA was markedly elevated (16.14 $\mathrm{nmol} / 1 \mathrm{per} \mathrm{hr})$ at a time when plasma aldosterone was low (86 pmol/1). Likewise, 8 am plasma ACTH (18 hr after corticosteroids) was elevated $(260 \mathrm{ng} / \mathrm{l})$ when plasma cortisol was 112 $\mathrm{nmol} / \mathrm{l}$. Adrenal antibodies were negative. He made an excellent recovery on appropriate replacement therapy with, in particular, marked improvement in his mental state.

\section{Case 3}

A 63-year-old male smoker with morning cough and sputum was found to have a right upper zone peripheral opacity on chest X-ray. There were no abnormal findings on examination and electrolytes were normal. At operation he underwent a right upper lobectomy as a frozen section of the biopsy showed anaplastic cells, but later definitive histology demonstrated tuberculosis. He was therefore commenced on rifampicin, isoniazid and ethambutol. Five days later he developed profuse diarrhoea and his blood pressure fell to $70 / 50 \mathrm{mmHg}$. Blood electrolytes were sodium $122 \mathrm{mmol} / 1$ and potassium $4.2 \mathrm{mmol} / \mathrm{l}$. When seen by the endocrine team after rehydration he described weight loss and anorexia for a few months, but had otherwise been well. There was a strong family history of thyroid disease, but not of Addison's disease. On examination blood pressure was $85 / 50 \mathrm{mmHg}$ lying and standing and he was not pigmented. Investigations demonstrated a normochromic anaemia (haemoglobin $10.2 \mathrm{~g} / \mathrm{dl}$ ), sodium $126 \mathrm{mmol} / 1$, potassium $4.7 \mathrm{mmol} / 1$, glucose 6.0 $\mathrm{mmol} / \mathrm{l}$, urea $7.3 \mathrm{mmol} / \mathrm{l}$ and creatinine $70 \mu \mathrm{mol} / 1$. The Synacthen test was flat (plasma cortisol 61 and $56 \mathrm{nmol} / 1$ before and one hour after respectively), ACTH raised (328 ng/l), PRA grossly raised (40.56 $\mathrm{nmol} / \mathrm{l} / \mathrm{hr}$ ) and aldosterone low (83 and $70 \mathrm{pmol} / \mathrm{l})$. Antibody screen was negative and thyroid function normal. He was treated with hydrocortisone which was rapidly reduced to maintenance values and the anti-tuberculous therapy stopped. He is now on a slightly larger dose of steroid than is usually required for maintenance and is well on his anti-tuberculous drugs.

\section{Discussion}

The increased pigmentation of the skin and mucous membranes in Addison's disease may vary in the light-skinned subject from a slight tan or a few 'black freckles' to an intense generalized pigmentation which has resulted in patients being mistakenly considered to be of a darker-skinned race. Most commonly, pigmentation is seen over extensor surfaces such as the back of the hands (phalangeal and metacarpophalangeal joints), elbows, knees, creases of the hands, at the dental gingival margin, on the lips, or on the buccal mucosa. Although excessive pigmentation is always quoted as being a cardinal sign of Addison's disease (Besser, 1978), these three consecutive cases which presented to us over a 3month period illustrate that this is not always so, despite raised levels of ACTH. Raised ACTH is thought to provoke the increase in skin pigmentation seen in Addison's disease. It is possible ACTH did not reach sufficient levels to cause such a reaction in these subjects (Rees, 1977). Unfortunately, in two of these cases treatment with steroids was started before blood had been taken for ACTH. A concentration of $816 \mathrm{ng} /$ litre was, however, recorded in Case 1, making a failure of pigmentary response rather than insufficient ACTH concentration the more likely explanation, at least in this subject. All these patients were in fact of fair complexion and had never tanned in earlier life. Vitiligo may mask skin darkening, but was not present in our cases.

The length of history in the first two cases ( 8 years and over 20 years respectively) is startling and certainly Case 2 had been severely affected for a large part of his life. None of the patients gave a history of an increased salt appetite or liquorice ingestion which could have provided partial treatment. It is likely that the shoplifting offence in Case 1 and the later diagnosis of early dementia were attributable to cortisol deficiency, particularly as there appears to be 
complete intellectual recovery after corticosteroid treatment.

Case 3 is also instructive and a reminder that enzyme inducing drugs may be dangerous in the setting of Addison's disease. The Addisonian crisis in this subject may have been precipitated by the addition of anti-tuberculous therapy, notably rifampicin which is a powerful enzyme inducer. It is, therefore, important to remember that patients on cortisol replacement therapy and anti-tuberculous drugs may need higher doses of steroid than normal.

In summary, these cases illustrate three major points.

(a) Despite the usual textbook descriptions, excess pigmentation is not necessarily a feature of Addison's disease making a high index of suspicion even more important in diagnosis. (b) The symptoms of Addison's disease may date back many years and may be responsible for years of mental and physical debility.

(c) Care must be taken when using enzyme inducing drugs, such as anti-tuberculous therapy, in such cases.

\section{Acknowledgment}

This work was supported in part by the MRC of New Zealand.

\section{References}

ADDISON, T. (1855) On the Constitutional and Local Effects of Disease of the Supra-Renal Capsules. Highley, London.

BESSER, M. (1978) The adrenal cortex. Medicine (Baltimore), 9, 419.

NERUP, J. (1974) Addison's disease-clinical studies. A report of 108 cases. Acta Endocrinologica, 76, 127.

REES, L.H. (1977) ACTH, Lipotrophin and MSH in health and disease. Clinics in Endocrinology and Metabolism, 6, 137. 